\title{
Tyre Purchasing by Civil Engineering Construction Companies - A Case Study of a Major Company in Africa
}

\author{
Elia Sousa \\ Krishna Govender \\ University of KwaZulu-Natal and Regenesys Business School Johannesburg, South Africa \\ krishnag@regenesys.co.za
}

Doi:10.5901/mjss.2014.v5n23p1797

\section{Abstract}

Although tyre expenses can be a significant component of the operating costs in civil engineering construction (CEC) companies, there are few studies investigating how the CEC industry can benefit by implementing specific tyre purchasing policies. The research aimed to highlight the expenditure on tyres, the factors affecting these, and how specific purchasing policies can impact on the total costs of purchases. A case study was conducted at XYZ-Eng-Africa, a major tyre purchaser in Africa by collecting data on tyre expenditure and supplier information from three countries in Africa (Angola, Malawi and Mozambique) for the period 2010-2012. It was ascertained that the expenditure on tyres depends on the size of the wheeled fleet and the diversity of the civil engineering equipment, resulting in a broad tyre supplier base which is difficult to manage. In addition, the focus is only on the ratio of price to quality, thus dismissing other important aspects of the purchasing process. It is recommended that the tyre purchasing policy of CECs should focus on implementing Supplier Relationship Management (SRM) strategies, and rationalizing the segmentation of the supplier base, and applying supplier performance measures. However, the success of SRM strategies may be affected by the lack of an integrated database of suppliers, and incorrect perceptions about purchasing. Nevertheless, CEC companies that focus on SRM policies in tyre purchasing may benefit from the flexibility to adapt to the market conditions and decrease total purchasing costs.

Keywords: civil engineering, tyres, purchasing policies, suppliers

\section{Introduction}

Civil engineering construction (CEC) is an important industry due to the capital invested in construction activities and high employment, and their contribution to a country's gross domestic product. The activities of multinational CEC companies in particular are subject to stress and risk, because of high competition on an international level and the global financial crisis. Faced with these challenges, the CEC industry became aware of the importance of productivity improvement, and most importantly overall cost reduction, and as the projects became larger and more complicated, the improvements focused on the procurement practices, labour efforts, construction planning, scheduling, engineering design, and organization (Choromokos and McKee, 1981).

Given the intensity of the activities in the CEC industry, operating costs which include tyre replacement are an important component of the total costs. Tyre replacement costs can be quite high, because CEC companies use a large variety of wheeled equipment for excavations, earthmoving, transportation, etc., and the implementation of specific purchasing policies can potentially result in cost savings. However, the precise estimation of operating costs is a difficult task in CEC, because operating costs are affected by many factors, inter-alia, tyre consumption (replacement) is a major expense in the CEC industry. The cost of tyre replacement is deducted from the delivered price and treated as an actual operating cost due to the short life of the tyre compared to the life of the machine that uses the tyres. The cost of tyre replacement is quite variable and determined by the cost of a new set of tyres, and the tyre life. In spite of other factors such as the type of tyres, working conditions and intensity of operations in the CEC are major determinants of tyre life. In addition, if the diversity of equipment is taken into account (different machines for different operations in different conditions), it is understood that purchasing tyres in the CEC sector becomes a challenging process. The implementation of strategic procurement practises should take into account the extent of these costs, so as to define proper cost saving policies.

Purchasing is a broad concept which includes all the activities conducted to obtain products from the supplier to its final destination, and thus purchasing decisions/policies have a profound impact on a company's financial performance, 
as they affect the direct materials costs and the net capital employed by the company (Van Weele, 2000). Although the adoption of a specific structure depends mainly on the characteristics of the business, an appropriate and efficient purchasing structure needs to overcome specific obstacles and pitfalls both at the operational and strategic levels (Nelson, Moody and Stegner, 2005), which in turn has led to the investigation of strategies to optimize the purchasing process and achieve the best possible outcomes. Strategies include implementing cost savings measures, evaluating the performance of a purchasing department, and using contracting and relationship management strategies. Companies have to select between different techniques (saving measures, contracting strategies and supplier relationship management strategies), and implement the technique that best fits their orientation, so as to optimize purchasing and achieve the best possible outcomes (Jones and Oliver, 2006; Temte, 2004; Bozarth et al., 1998).

In view of the above, this study will investigate the tyre purchasing in CEC companies using XYZ-Eng-Africa as a case study, to explore the tyre replacement costs and the appropriate tyre purchasing policies such as the use of contracting strategies and supplier relationship management (SRM) strategies in order to reduce costs and contribute to the overall financial performance of CEC companies. The aforementioned will be addressed through the following:

- Determining tyre demand and replacement costs in XYZ-Eng-Africa for the period 2010-2012, so as to estimate the size of these costs and highlight their importance in the overall operating costs.

- Investigating the appropriate purchasing policies that should be implemented for tyres in CECs in order to reduce tyre expenses.

- Analyzing why some purchasing policies cannot be implemented, although they are known to optimize purchasing strategies, and

- Estimate the potential benefits of selected tyre purchasing policies in the overall cost savings for CEC companies.

\section{Research Context}

$\mathrm{XYZ}$-Eng operates in inter-alia, civil engineering and construction of infrastructure, and has many branch operations in Europe, America and Africa, with the African business segment accounting for $39 \%$ of the total turnover of the civil engineering and construction business, and $31 \%$ of the total turnover of the XYZ- Eng Group. Furthermore, XYZ-EngAfrica increased its turnover in 2010 by $26 \%$ to $€ 626$ million and accounts for $39 \%$ of the total turnover of the engineering and construction area, and 31\% of the total volume of the XYZ-Eng Group (Mota-Engil, 2013). As the most important and active branch of the group, XYZ-Eng-Africa maintains a large fleet of wheeled equipment which operates in three important countries (Angola, Malawi and Mozambique) on the African continent, under different conditions, and with high tyre replacement. Given the size of XYZ-Eng-Africa's operations, and the fact that the company maintains a large fleet of a variety of wheeled equipment, it was therefore considered for investigation thorough a case study.

\section{Research Methodology}

The case study was conducted through analysis of the 'wheeled' fleet tyre consumption data from Angola, Malawi and Mozambique over a 3-years period (2010-2012), as well as data from suppliers for the same period. The steps for conducting a case study suggested by Yin (1994) were closely followed, and data was collected on tyre replacement expenses in the company, as well as on the tyre purchasing policies being implemented. Thereafter, the information from the quantitative and qualitative data were triangulated to highlight the major expense of tyre replacement through purchase, current purchasing policies and, the possible benefits of implementing certain purchasing optimization techniques.

The data on tyre purchasing by XYZ-Eng-Africa were collected from the company records held at the procurement offices. The data included the tyre expenses by tyre type and order volume for the last 3 years (2010-2012), for Angola, Malawi and Mozambique. This approach aimed to increase the reliability of the data, since the activities as well as the intensity of operations differed between countries. The data files contained information about the tyre orders, the units ordered per tyre type and the price per unit, and the list of suppliers from whom the tyres were purchased. Secondary data also collected from the records of XYZ-Eng-Africa procurement headquarters. The data were considered to be trusted, since XYZ-Eng-Africa is a listed multinational conglomerate, which is obligated to provide financial and operations performance, and future plans to investors.

The recorded data was used to estimate tyre expenses by considering, the annual tyre expenses per country for the 3-year period of the study, tyre expenses per tyre type, and equipment diversity. In addition, suppliers were analyzed 
in terms of the number used by the company, and in terms of their percentage share of the company's tyre expenditure. The number of suppliers and their share in XYZ-Eng-Africa's tyre expenditure was compared with the equipment diversity, in order to understand how the supplier base is developed per country.

An effort was made to increase the validity of the study, by including data from three countries for a period of three years (Brymann and Bell 2003). In addition, the data was considered valid because it was strictly controlled and continuously updated, and the respondents from the relevant offices were also qualified to compile the data. Furthermore, the findings from the recorded data were triangulated with the information from other documents.

In case studies, the term reliability can be quite unclear because measures cannot be easily defined, thus it is translated to repeatability and actually shows whether another researcher gets the same or similar results and arrives at similar conclusions when conducting the same or similar research. The reliability of the research results depended primarily on the nature of the data used, since the recorded data is somewhat unique to XYZ-Eng-Africa and, cannot be considered fully replicable in general to all CEC companies.

Standard ethics requirements were met by maintaining active communication with the respondents and caution was exercised to minimise ethical risks by using the pseudonym XYZ-Eng-Africa. The recorded data was used through the written consent of the executive officer in the African branch.

\section{Findings}

The type and the size of the 'wheeled' equipment for Angola, Malawi and Mozambique, are illustrated in figures 1, 2 and 3 , respectively. It became evident that the fleet in Angola consisted of a total 184 wheeled units, mainly excavators (28\% of the fleet), steer wheel and back hoe loaders (10\% and $6 \%$ of the fleet, respectively), graders (18\%), drum rollers (7\%), bulldozers (5\%) and articulated dump trucks (6\%). In Malawi, on the other hand, the wheeled fleet is larger and different from that of Angola, in that it had 320 units, consisting primarily of pick-up cabs (approximately 24\% of the fleet) and tip trucks (11\% of the fleet). The type of 'wheeled' equipment in Mozambique has a similar pattern to that in Malawi, consisting mainly of pick-up cabs (36\% of the fleet) and rear tipper trucks (24\%), although the size of fleet is smaller (215 wheeled units vs. 320 in Malawi).

It was ascertained that the wheeled fleet in the African region is quite large consisting of approximately 719 units, and different between and within the countries of the region, due to the diverse nature of operations. It is clear from Table 1 that the equipment diversity index in Angola (10.3\%) is quite low compared to that in Malawi (20.0\%), implying that there are 19 different categories of the total (184) wheeled vehicles in Angola compared to 64 different categories of 320 wheeled vehicles in Malawi. Although the equipment diversity index in Mozambique (9.3\%) was similar to that of Angola, the equipment in Mozambique consisted predominantly of light duty (36\%) and heavy duty (24\%) vehicles, whereas in Angola the majority of the wheeled equipment includes heavy duty vehicles (>60\%). In Malawi, only $35 \%$ of the wheeled equipment consists of light and heavy duty vehicles, with the majority being mainly intermediate duty vehicles.

Table 1. Diversity index of wheeled equipment in Angola, Malawi and Mozambique

\begin{tabular}{|c|c|c|c|c|}
\hline Country & $\begin{array}{c}\text { Total wheeled } \\
\text { equipment (units) }\end{array}$ & $\begin{array}{c}\text { Categories of wheeled } \\
\text { equipment }(\mathrm{n})\end{array}$ & $\begin{array}{c}\text { Equipment diversity } \\
\text { index }(\%)^{\mathrm{a}}\end{array}$ & $\begin{array}{c}\text { Predominant type of } \\
\text { equipment }\end{array}$ \\
\hline Angola & 184 & 19 & 10.3 & Heavy duty $(>60 \%)$ \\
\hline Malawi & 320 & 64 & 20.0 & $\begin{array}{c}\text { Light duty }(\approx 24 \%), \text { heavy } \\
\text { duty }(11 \%)\end{array}$ \\
\hline Mozambique & 215 & 20 & 9.3 & $\begin{array}{c}\text { Light duty }(36 \%) \text {, heavy } \\
\text { duty }(24 \%)\end{array}$ \\
\hline
\end{tabular}

a Diversity index was calculated as: 100×Equipment categories/Total equipment.

Source: XYZ-Eng-Africa Procurement Data.

While the wheeled fleet differs between and within countries, as reflected in table 1, it needs to be noted that the equipment is used in different intensities according to the operating activities, and is subjected to different wear due to the different surface conditions. This means that there are different tyre demands, in total and per tyre type on an annual basis between countries, which are difficult and complicated to interpret and standardize. On an annual basis, approximately 2.64 million USDs are spent in the African region for tyre purchasing (1.37 million in Angola, 1.2 million in Malawi and 0.07 million in Mozambique). 
Taking into account the data from table1, it is evident that tyre expenses do not depend on the size of the wheeled equipment, because in Malawi although the size of the fleet was larger than that of Angola, the total tyre expenses were somewhat lower. This means that tyre expenses depend on the type of equipment (tyre type), which alters the average tyre cost per unit of equipment, as indicated in table 2.

Table 2. Average tyre cost per unit of wheeled equipment (2010-2012) in the Africa region

\begin{tabular}{|c|c|c|c|c|}
\hline Country & $\begin{array}{c}\text { Predominant type of } \\
\text { equipment }\end{array}$ & $\begin{array}{c}\text { Total wheeled } \\
\text { equipment (units) }\end{array}$ & $\begin{array}{l}\text { Total tyre expenses } \\
\text { (USD; 2010-2012) }\end{array}$ & $\begin{array}{c}\text { Average tyre cost per unit of } \\
\text { equipment (USD) }\end{array}$ \\
\hline Angola & Mainly heavy & 184 & 4111258 & 22343,8 \\
\hline Malawi & Light/intermediate & 320 & 3849547 & 12029,8 \\
\hline $\begin{array}{c}\text { Mozamb } \\
\text { ique }\end{array}$ & Mainly light & 215 & 229704 & 1068,4 \\
\hline
\end{tabular}

${ }^{a}$ Average tyre cost was calculated as: Total tyre expenses/Total units of wheeled equipment

Source: XYZ-Eng-Africa Procurement Office Data.

This approach although not very precise, nevertheless indicates that the type of equipment affects the average tyre expenses. For example in Angola, where heavy equipment is mainly used, the average tyre cost per unit of equipment is higher, simply because the cost of a set of tyres for this equipment is very high. On the contrary, in Mozambique, where light vehicles are mainly used, the average tyre cost per vehicle unit is lower.

\subsection{Tyre suppliers to XYZ-Eng-Africa}

An analysis of the data showed that the number of suppliers, as well as the tyre expenses per supplier was different among the three countries. In Angola, 11 tyre suppliers were used during the review period, and $52 \%$ of the total tyre expenses were incurred with one supplier, whilst the remaining (48\%) was allotted to four suppliers. On the other hand in Malawi, the situation was quite different to that of Angola, in that 19 tyre suppliers were used, and $60 \%$ of the total tyre expenditure was incurred with two suppliers. Notably, the remaining $40 \%$ of the expenses was divided among 6-7 suppliers. In Mozambique, the image of supplier base was similar to that in Angola, with $77 \%$ of the total tyre expenses were held by one supplier and the remaining $23 \%$ was divided among three suppliers.

\subsection{Relationship between the type of equipment and the supplier base}

A central question arising from the reported supplier data concerned the factor(s) that led to supplier segmentation in the three countries, which actually reflected different purchasing policies in different markets. One factor which could have contributed to this is the different construction and engineering activities in each country (market), which required different equipment, operating under different conditions. An attempt was made to investigate potential relationship between equipment diversity and supplier segmentation.

For convenience reasons, the tyre suppliers in each country were classified according to their share of the tyre expenditure of XYZ-Eng-Africa, as follows:

- Primary supplier: contributed to more than $30 \%$ of the total tyre expenses during 2010-2012;

- Secondary supplier: contributed between $10 \%$ to $30 \%$ of the total tyre expenses during $2010-2012$; and

- Small supplier: contributed to less than $10 \%$ of the total tyre expenses during 2010-2012.

The data on equipment diversity index (from table 1) was plotted (figure 1) together with the total number of tyre suppliers, and the total share of the primary, secondary and small suppliers per country. Since there was only one line of data for each country, complex correlations could not be performed, and this was selected as the simplest way to detect potential relationship among the parameters.

It is clear from figure 1, that when equipment diversity increases, the supplier base is expanded (more suppliers are used). For example, the equipment diversity in Angola (10.3\%) and in Mozambique (9.3\%) is lower than that in Malawi (20\%). As a consequence, the number of tyre suppliers in Angola (11) and Mozambique (9) are lower than that in Malawi (19). This indicates that when a broad variety of wheeled equipment are operated (as is the case of Malawi), there is need for a broad variety of tyre types, which cannot be satisfied by a few suppliers. Therefore, the supplier base has to be expanded to meet the requirements. On the other hand, when equipment diversity is low (few categories of wheeled 
equipment), as is the case of Angola and Mozambique, the tyre demands can be satisfied by a few suppliers, thus decreasing the size of suppliers' base.

Figure 1. Relationship between equipment diversity and supplier base segmentation during the period 2010-2012.

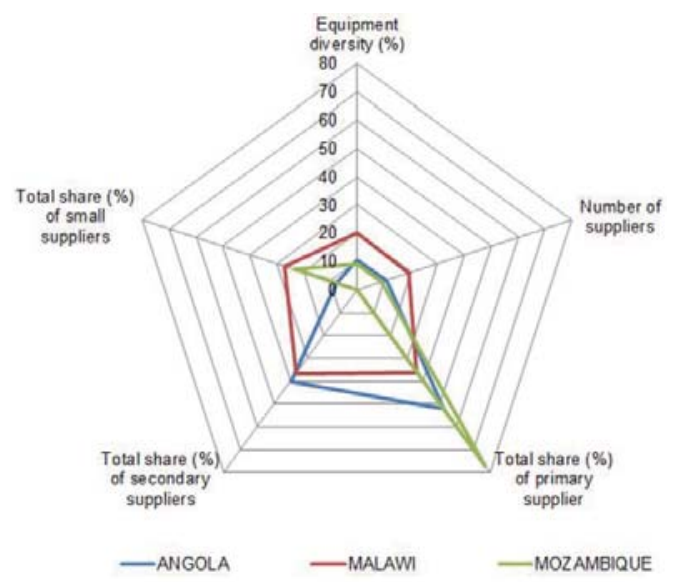

Source: Procurement Records 2010-2012.

The effects of equipment diversity are not limited only to the number of tyre suppliers as it also has a profound effect on the segmentation of the supplier base in terms of expenses per category of supplier. When equipment diversity increases (Malawi), the total tyre expenses are almost equally allotted among the primary, secondary and small suppliers and, the primary supplier cannot be clearly identified. On the other hand, the low equipment diversity index reduces the segmentation of the supplier base, hence, it can be seen that there is a primary supplier with a central role in Angola (52\% of the tyre expenses), and in Mozambique (77\% of the tyre expenses), and clearly distinguished secondary suppliers (in Angola 40\% of tyre expenses) or small suppliers (in Mozambique).

\subsection{Tyre Purchasing Policy at XYZ-Eng-Africa}

XYZ-Eng Group has a centralized organizational model, one which designates XYZ-Eng-Africa head office as the central procurement office of the African region. Although there is no specific procurement manual to guide the purchasing process, staff do follow some general guidelines, which is similar to the purchasing process model of Van Weele (2000). During the sourcing process, the market is analyzed to identify suppliers, determine specification for tyres, select suppliers, negotiate and establish agreements. At the sourcing stage, the appropriate procurement officer (with technical qualifications on tyres) plays the role of the leader buyer and attempts to prepare and negotiate the agreement, according to the order entries from the internal customers (branches in each country).

The second stage of the purchasing process often referred to as "purchase-to-pay" stage, is initiated from the internal end user (country branch). The demand is processed through ordering, receipting, and payment, so that the end user can get the tyres. This is actually the practical part of the process when tyres are purchased in a physical sense. If the procurement officers have undertaken extensive evaluations of the sources, not much needs to be done at the purchase-to-pay process (except for putting in a request for purchase), and therefore, the selection of the supplier. The purchase-to-pay process is performed by the procurement officers because the strategic sourcing process is centralized, and all requests for purchase go through the central process. The procurement officers are also responsible of keeping the feedback on tyre supplier performance, and the performance of the officers is evaluated monthly by a sub-system, which measures the ratio of processed orders to order entries (direct observation).

According to Van Weele's (2002) purchasing model, the procurement head office of XYZ-Eng-Africa appears to be adopting the main policies of the purchasing coordination, savings through synergy model in tyre purchasing. This is explained by the fact that the coordinated purchasing is controlled by a central procurement department, which along with price and costs, handles carefully the quality level of purchased tyres due to their important influence on the operating capability of the wheeled fleet. The procurement officers have a good purchasing background with analytical and communication skills. Furthermore, supplier management plays an important role and aims mainly at adopting different 
strategies for different countries, which are actually defined by the conditions. For example, the high equipment diversity in Malawi requires a large variety of tyres, and in turn a broad supplier base.

\section{Discussion of Key Findings}

A characteristic of the supplier was that there were no key suppliers, since several suppliers shared the investment of XYZ-Eng-Africa in tyre purchasing. However, according to Dyer et al. (1998) and Hoyt and Huq (2000), two strategic, namely, those contributing to between $36 \%$ and $37 \%$ of XZY-Eng-Africa's tyre expenses, and several non-strategic suppliers, namely, those sharing between $3 \%$ to $13 \%$ of XZY-Eng-Africa's tyre expenses, could be distinguished. Therefore, relationships with the (strategic) supplier can be built, because of the market conditions and/or specific company conditions, for example, the need for a specific product that only a particular supplier is providing, whereas dependency on the non-strategic suppliers is minimized (Dyer et al., 1998; Hoyt and Huq, 2000). Although it is not always feasible to reduce the supplier base in tyre purchasing, supplier selection can be rationalized, so as to select a few key suppliers (Berger and Zeng, 2006). This can be done by using specific determinants, in addition to those used currently (i.e. low price in some cases or value for money tyres in other cases), such as the competence, financial stability and the delivery times of suppliers. An important aspect also is, understanding the pricing model of the suppliers, which would be valuable for successful negotiations and decision making (Jones and Oliver, 2006). Long-term, as far as possible, cooperative relationships established particularly with the key or strategic suppliers can serve as a tool to show trust for the supplier and build a confidence relationship (Ring and van de Ven, 1994). The long-term relationships can also work as an incentive for suppliers to improve the aforementioned quality parameters (Darvik and Larsson, 2010). Thus, to optimize tyre purchasing, a proper policy should focus on implementing specific SRM strategies, since one of the basic techniques to optimize SRM is reduced supplier base (Juran and Godfrey, 1998). The same SRM strategy does not necessarily have to be applied to all the suppliers, but can be differentiated between strategic and non-strategic suppliers which, is the usual purchasing policy nowadays in many companies (Gelderman and Van Weele, 2003).

It became apparent that no "proper" supplier segmentation could be undertaken in the heavy equipment tyre purchasing process. The main determinant for selecting the segmentation model is the characteristics of the product (tyres in this case) to be purchased, which in the present case study depend on the equipment diversity, operating intensity etc. Another issue to be kept in mind is that the tyre suppliers of XYZ-Eng-Africa are just representatives and not tyre manufacturers. Therefore, segmenting the supplier base depends on which representative sells tyres to cover the specific needs of the company at a given time. However, the supplier segmentation must be combined with other factors, which affect the nature of the supplier relationship management, such as the selection of the proper supplier(s), understanding the pricing model of the supplier (which is an approach to supplier base development) and supplier quality management. The selection of the proper supplier is usually based on product quality, suppliers' competence and financial stability, flexibility and delivery times (Goffin et al., 2006). Since tyre quality is a matter of the manufacturer, the selection of suppliers by XYZ-Eng-Africa procurement officers lies more on the combination of price and quality, rather than on competence, financial stability and delivery times. By understanding the supplier's price-setting strategy a buyer acquires valuable knowledge for the supplier choice process, and for the price fluctuations over time, which gives an advantage for successful negotiations and decision making (Jones \& Oliver, 2006).

Because the purchasing department does not generate revenues as such, its contribution to a company's profit is by default negative, implying poor financial performance that delivers increasing costs (Juzokaitè and Trainavičiütè, 2009). The increasing costs in turn compel the company to achieve financial savings, by increasing purchasing efficiency mostly in terms of price (Pooler and Pooler, 1997). Although price reduction is the major parameter when procuring material, if price is the only parameter that is considered, then there is the risk of increasing other costs within the company, which will eventually reduce or even eliminate the costs savings (Bertelsen and Nielsen, 1997). A large number of companies within the construction industry focus on price reduction as the main purchasing strategy and CEC companies are too often only considering cheapest price when procuring several materials. Due to this, they have begun to realize the problems with having price as their main focus, because prices are pushed to the limit of what suppliers can afford, leaving no room for additional reductions (Darvik and Larsson, 2010). If the price of tyres are considered without taking into account tyre quality, and suppliers performance and quality, then costs are transferred from procurement to production department and do not really reduce (any observed reduction in tyre expenses is fictitious) (Darvik and Larsson, 2010). 


\section{Conclusion}

With regard to the research questions, it can be concluded that tyre replacement costs in CEC companies are a significant component of the wheeled fleet operation. To address these costs, tyre purchasing policies should focus on SRM strategies, in view of the rationalized segmentation of the supplier base, the implementation of long-term relationship-oriented coordination with the strategic suppliers, and the application of quality and performance management systems, which will ensure a smooth purchasing process.

When purchasing tyres the procurement officers at XYZ-Eng-Africa should, work on a basis of other value adding factors as well, such as product quality and product performance. However, price reduction cannot be achieved by XYZEng-Africa alone, but depends on the level of collaboration and cooperation with the supplier(s). This highlights the important role of the suppliers in achieving price reductions in tyre purchasing.

Tyre supplier quality management is a more complex issue, since the most important quality dimensions would be performance (tyres' technical specifications and operating characteristics), reliability (the probability of a tyre to fail over a specified period of time under stated conditions of use), conformance (the degree to which delivered tyres meet the requirements and the standards), and availability (accessibility to tyres) and e) serviceability (the speed and ease of repairing an item or having it repaired when slightly damaged, but not completely ruined).

A reduced supplier base is not always feasible at XYZ- Eng Africa due to the diverse nature of tyres. Thus, tyre replacement costs can be very high and complicated, thus adding significantly to the operating costs of a CEC company. Tyre replacement costs are determined by the cost of a new set of tyres, and the tyre life, which is largely defined by the working conditions.

One objective of this study was to highlight the size of tyre replacement costs in CEC companies. It became evident that tyre replacement costs do not solely depend on the size of the wheeled fleet in a CEC company, but they are rather a function of the type of equipment in use, which implies that tyre type is the determinant. The research findings indicated that in Angola the tyre expenses were higher compared to Malawi, despite the smaller wheeled fleet, due to the fact that the Angolan fleet consisted mainly of heavy equipment, for which, tyre replacement per unit of equipment costs more. In addition, the heavy equipment works under harsher conditions; hence, tyre life is negatively affected.

\section{Recommendations}

The complex issue of the suppliers' quality management should be addressed with more attention. Along with accessibility to tyres and the speed and ease of repairing a damaged tyre, performance and reliability of tyres should be considered as important supplier quality indices. To achieve this, suppliers must be perceived as partners, not as rivals, and their valuable knowledge in tyre specifications should be taken advantage of in tyre purchasing. This means that $X Y Z$-Eng-Africa needs to be flexible and be able to segment the supplier base according to the conditions. It was also recommended that XYZ-Eng-Africa should focus more on SRM strategies, by bringing together the rational segmentation of the supplier base (based on competence, stability, understanding pricing model), the quality management and performance measure of the suppliers and the adoption of different approaches for different suppliers.

CECs must create a central integrated supplier database containing information about the status, stability, competence, types of tyres, frequency of purchasing specific types of tyres from a supplier in a stated period, profiles, and quality management and performance measures. Based on this data, negotiations can be better and several decisions can be made on the strategic level (e.g. exclude a supplier due to low performance).

Suppliers' performance should be managed and measured, since this is of great importance when evaluating suppliers, because it contributes to objective supplier selection. Measurement of all suppliers' performance will probably be too time-consuming; hence, a recommendation is to start with the key suppliers.

CECs should consider the total tyre purchasing costs and not only the highest quality and the lowest price, because there is a risk of dismissing other equally important and costly aspects of tyre purchasing.

Despite the current "unwillingness' of both parties to be committed, contracting should be considered, since such an effort would highlight the potential impact on reducing total tyre purchasing process costs. A long term contract will probably be too risky; hence, a recommendation is to start with a short term contract.

\section{Limitations of the Study and Future Research}

One of the main limitations of using a single case study is that it raises questions about how well you can generalise the findings from one single case to comparable situations. In this study it is stated that the purpose of the case study is to 
ascertain possible benefits of tyre purchasing policies to CEC companies. The issue of generalization is somewhat resolved by using this case as an exploratory study to provide illustrations in support of quantitative data.

The case study was the only method for empirical investigation. It is thus necessary to conduct further research in order to contribute to and develop the framework and its application.. A more extensive survey should be conducted in order to confirm the results of the present study. The proposed tyre purchasing policies could be tested in other procurement aspects, such as maintenance, repair, and other operating supplies, capital goods and services in CEC industry.

\section{References}

Berger, P.D, Zeng, A.Z. (2006). Single versus multiple sourcing in the presence of risks. Journal of Operational Research Society 57: 250-261.

Bertelsen, S., Nielsen, J. (1997). Just-In-Time Logistics in the Supply of Building Materials. International Conference on Construction Industry Development: Building the future Together, 9-11.

Bozarth, C., Handfield, R., Das, A. (1998). Stages of global sourcing strategy evolution: an exploratory study. Journal of Operations Management 16: 241-255.

Brymann, A., Bell, E. (2003). Business research methods. Oxford University Press, New York.

Choromokos, J., McKee, K.E. (1981). Construction productivity improvement. Journal of Construction Division 107, 35-47.

Darvik, L., Larsson, J. (2010). The impact of material delivery deviations on costs and performance in construction projects. Master's Thesis in the Design and Construction Project Management, Department of Civil and Environmental Engineering. Chalmers University of Technology, Göteborg, Sweden 2010.

Dyer, J.H., Cho, D.S., Chu, W. (1998). Strategic supplier segmentation: the next "best practice" in supply chain management. California Management Review 40 57-77.

Goffin, K., Lemke, F., Szwejczewski, M. (2006). An exploratory study of 'close' supplier-manufacturer relationships. Journal of Operations Management 24: 189-209.

Hoyt, J., Huq, F. (2000). From arms-length to collaborative relationships in the supply chain. An evolutionary process. International Journal of Physical Distribution and Logistics Management 30: 750-764.

Jones, B., Oliver, J. (2006). Measuring purchasing performance. The Chartered Institute of Purchasing \& Supply. CIPS Publications, UK. Juran, J.M., Godfrey, A.B. (1998). Quality in Supplier Relations. McGraw-Hill Professional.

Juzokaitè, E., Trainavičiūtè, L. (2009). Procurement optimisation based on balanced scorecard. Implementation guidelines for pharmaceutical industry. Master's Thesis for Aalborg University Master's Program in Internationa Business, Denmark, 2009.

Mota-Engil (2013). Consolidated report and accounts 2012 [online]. Available from: http://www.mota-engil.pt//nvestorBoard.aspx? contentld=131\&Language $=2$ [accessed 15 April 2013].

Nelson D., Moody P.E., Stegner J.R. (2005). The 10 Procurement Pitfalls, Supply Chain Management Review, April 2005.

Pooler, V.H. and Pooler, D.J. (1997). Purchasing and Supply Management: Creating the Vision. Chapman \& Hall, New York.

Ring, P.S., Van de Ven, A.H. (1994). Developmental processes of cooperative interorganizational relationships. Academic Management Review 19: 90-118.

Temte, A. (2004). Financial Statement Analysis. Dearborn Trade, A Kaplan Professional Company, 2004.

Van Weele, A. (2002). Purchasing and Supply Chain Management: Analysis, Planning and Practice (3rd edition) Thomson Learning, London.

Van Weele, A.J. (2000). Purchasing Management: Analysis, Planning, and Practice. Second Edition. International Thomson Business Press. London.

Yin, R.K. (2003). Case Study Research - Design and methods (3rd ed). London: Sage Publications. 